\title{
Solid particle erosion and viscoelastic properties of thermoplastic polyurethanes
}

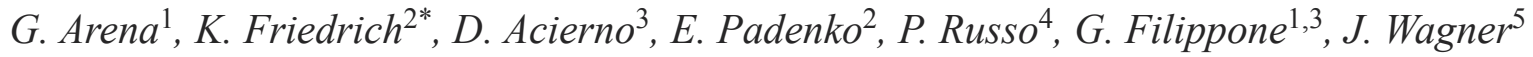 \\ ${ }^{1}$ Department of Chemical, Materials and Production Engineering, University of Naples Federico II, P.le Vincenzo Tecchio \\ 80, 80125 Naples, Italy \\ ${ }^{2}$ Institute for Composite Materials (IVW GmbH), Technical University of Kaiserslautern, 67663 Kaiserslautern, Germany \\ ${ }^{3}$ INSTM - Reference Centre for Processing Technologies of Polymer and Composites, University of Naples Federico II, \\ P.le V. Tecchio 80, 80125 Naples, Italy \\ ${ }^{4}$ Institute for Polymers, Composites and Biomaterials, National Council of Research, Via Campi Flegrei 34, 80078 \\ Pozzuoli, Naples, Italy \\ ${ }^{5}$ Bayer MaterialScience Aktiengesellschaft, BMS-CAS-SB-SF-SP, Leverkusen, Germany
}

Received 15 September 2014; accepted in revised form 31 October 2014

\begin{abstract}
The wear resistance of several thermoplastic polyurethanes (TPUs) having different chemical nature and micronscale arrangement of the hard and soft segments has been investigated by means of erosion and abrasion tests. The goal was correlating the erosion performances of the materials to their macroscopic mechanical properties. Unlike conventional tests, such as hardness and tensile measurements, viscoelastic analysis proved to be a valuable tool to study the erosion resistance of TPUs. In particular, a strict correlation was found between the erosion rate and the high-frequency $\left(\sim 10^{7} \mathrm{~Hz}\right)$ loss modulus. The latter reflects the actual ability of TPU to dissipate the impact energy of the erodent particles.
\end{abstract}

Keywords: damage mechanism, solid particle erosion, thermoplastic polyurethanes, wear, material testing

\section{Introduction}

Erosion is a dynamic process that causes material removal from a target solid surface. The most severe erosion case is that occurring as a consequence of the impingement of solid particles, having a high momentum and, in particular, a very high velocity. This process causes wear of materials, surface degradations and reduction in functional life of the structural components. As pointed out by Barkoula and Karger-Kocsis [1], solid particle erosion, similarly to other tribological processes, is a combined process: the mechanical load may be associated with secondary thermal, chemical and physical phenomena between the counterparts involved in the tribological system.
The classification of various materials with reference to their erosive wear shows remarkably differences, particularly when the variation in the impactangle and impact-time is taken into account. The mechanisms can be categorized as ductile and brittle. The ductile erosion may involve an incubation period whereby the mass of the target initially increases, and then sets down to a steady state condition; for normal impacts, the latter is due to an early embedding of particles in the relatively soft target surface [2]. It is also known that in ductile mode the maximum material removal occurs at low impingement angles, whereas this maximum is found at high impingement angles when brittle erosion dominates. Fiber reinforced polymers are con-

\footnotetext{
${ }^{*}$ Corresponding author, e-mail: klaus.friedrich@ivw.uni-kl.de (C) BME-PT
} 
sidered as having a semi-ductile erosion behaviour, for which the maximum is at an angle between ca. 45 to $60^{\circ}[3,4]$.

Polymer-based materials can be profitably used as coating of components subjected to erosion as they provide them with a high impact absorbing ability [5-7]. Among other polymers, thermoplastic polyurethanes (TPUs) have attracted a significant attention in this respect, due to their good processability and unique properties deriving from their peculiar molecular structure. TPUs are multiphase block copolymers characterized by a sequence of hard and soft blocks having glass transition temperature $\left(T_{\mathrm{g}}\right)$ and melting point $\left(T_{\mathrm{m}}\right)$ well below and well above the room temperature, respectively [8]. Due to these unique features, TPU exhibits high impact absorbing ability and, at the same time, a sufficiently high modulus. This makes TPUs suitable for protective coating or films with minimal erosive wear, which can strongly limit the consequences of erosion processes in environments where highspeed particles may hit surfaces [9].

The amount of material removal during erosion depends on many interrelated factors, which include the properties and structures of the target material as well as the physical and chemical characteristics of the erodent particles. The difficulty to control and model so many factors and processes makes the tribological system generally complex. This aspect appears even more pronounced for coating made of TPUs. Several attempts have been done in the last years aimed at correlating their performances with their morphological and mechanical features, but there is a lack of general agreement in the role played by the various parameters involved [1]. The $T_{\mathrm{g}}$, in terms of both its absolute value and its relative position with respect to the operating temperature, certainly affects the erosion rate. In addition, molecular and morphological parameters, such as presence of crosslinks, relative content of hard and soft phase, and degree of phase separation between soft and hard segments (that in turn depends on the molecular weight of the elastomer and its chemical composition) have a strong influence on the erosion behaviour $[9,10]$. Besides, macroscopic mechanical features affect the solid particle erosion resistance. In particular, a correlation was found between the erosion resistance and the rebound resilience, defined as the absorbed amount of initial energy of the impact particles [11]. Viscoelasticity was consid- ered to be important as well. Comparing different kinds of elastomers Slikkerveer et al. [6] concluded that polymers having a pronounced 'rubber-like' behaviour generally exhibit a better erosion resistance. Generally speaking, softer elastomers usually show a better solid particle erosion resistance because of less crack propagation and more elastic/plastic deformation [9], while harder TPU's systems normally exhibit higher wear resistance [12].

To resume, although some interesting trends have emerged about the effects of different factors influencing polyurethanes erosion, identifying general trends and relationships remains an ambitious challenge. A serious attempt in this direction has been recently done by Cizmas and Slattery [13], who proposed a dimensionless elastic modulus to rationalize the results by Li and Hutchings [14] on a series of polyurethanes. This study aims for the same goal, that is looking for general relationships between the erosion behavior and the main properties of different kinds of TPUs. In particular, the sand erosion of seven commercial grade TPUs has been investigated at different impingement angles. Before erosion testing, the materials were thoroughly characterized by means of different techniques, including their microstructural analysis and their dynamicmechanical properties. This resulted finally in a clear relationship between the erosion mass loss and the viscoelastic properties, in particular with the loss flexural modulus $E^{\prime \prime}$ (provided the latter was estimated on the proper timescale).

\section{Experimental}

\subsection{Raw materials and preliminary characterization}

Seven different TPUs, all produced by Bayer MaterialScience $\mathrm{AG}$ and commercialized with the trade name of DESMOPAN ${ }^{\circledR}$, were examined in this study. The pure materials were subjected to a preliminary characterization, whose results are summarized in Table 1.

\subsection{Microstructural analyses}

Transmission electron microscopy (TEM) analysis was carried out using a Philips EM 208S TEM apparatus. In details, after embedding in acrylic resin, small pieces of samples, pre-conditioned at $120^{\circ} \mathrm{C}$ for $72 \mathrm{~h}$, were trimmed into pyramidal shapes. Ultrathin sections (60 $\mathrm{nm}$ thick), obtained using a Reichter-Jung ultramicrotome fitted with a diamond 
Table 1. Main TPU properties

\begin{tabular}{|c|c|c|c|c|c|c|c|c|c|}
\hline $\begin{array}{l}\text { Code } \\
\text { name }\end{array}$ & $\begin{array}{l}\text { Grade } \\
\text { name }\end{array}$ & $\begin{array}{c}\text { Chemical } \\
\text { basis }^{1}\end{array}$ & $\begin{array}{c}\text { Density }^{2} \\
{\left[\mathrm{~g} / \mathrm{cm}^{3}\right]}\end{array}$ & $\begin{array}{c}\text { Hardness } \\
\text { [Shore A] }\end{array}$ & $\begin{array}{c}\text { Elastic } \\
\text { modulus }^{4} \\
{[\mathrm{MPa}]}\end{array}$ & $\begin{array}{l}\text { Tensile } \\
\text { stress }^{4} \\
{[\mathrm{MPa}]} \\
\end{array}$ & $\begin{array}{c}\text { Deformation } \\
\text { at break } \\
{[\%]} \\
\end{array}$ & $\begin{array}{c}\text { Degradation } \\
\text { temperature }^{5} \\
{\left[{ }^{\circ} \mathrm{C}\right]} \\
\end{array}$ & $\begin{array}{c}T_{g}(\text { soft } \\
\text { segments) } \\
{\left[{ }^{\circ} \mathrm{C}\right]} \\
\end{array}$ \\
\hline TPU 1 & $9385 \mathrm{~A}$ & ether & 1.12 & 86 & $27.8 \pm 1$ & $47.9 \pm 3$ & $773.3 \pm 17$ & 292 & -50 \\
\hline TPU 2 & 487 & ester & 1.20 & 85 & $23.2 \pm 3$ & $55.9 \pm 5$ & $633.2 \pm 34$ & 304 & -41 \\
\hline TPU 3 & $385 \mathrm{~S}$ & ester & 1.21 & 84 & $25.4 \pm 0.2$ & $43.3 \pm 8$ & $691.6 \pm 61$ & 300 & -42 \\
\hline TPU 4 & DP2587A & ester & 1.19 & 86 & $29.3 \pm 3$ & $60.4 \pm 5$ & $737.0 \pm 24$ & 300 & -43 \\
\hline TPU 5 & DP1085A & ester & 1.20 & 83 & $23.5 \pm 2$ & $44.9 \pm 1$ & $857.6 \pm 8$ & 286 & -42 \\
\hline TPU 6 & 1089A & ester & 1.20 & 88 & $43.6 \pm 0.4$ & $54.0 \pm 3$ & $710.7 \pm 20$ & 292 & -40 \\
\hline TPU 7 & $786 \mathrm{E}$ & carbonate & 1.15 & 86 & $28.8 \pm 3$ & $35.6 \pm 1$ & $647.5 \pm 10$ & 282 & -36 \\
\hline
\end{tabular}

${ }^{1}$ According to producers. ${ }^{2}$ From technical datasheet. ${ }^{3}$ Measured through hardness Shore A. ${ }^{4}$ Measured from tensile tests. ${ }^{5}$ Measured through TGA analyses. ${ }^{6}$ Measured through DSC analyses.

knife, were placed on a copper grid and stained with uranyl acetate and lead citrate which preferentially dyes the soft segments [15].

Small angle X-ray scattering (SAXS) analyses were performed using a SAXSess diffractometer (Anton Paar, Austria) equipped with a $\mathrm{CuK}_{\alpha}$ radiation source $(\lambda=0.1542 \mathrm{~nm})$. The spectra were collected at $30^{\circ} \mathrm{C}$ in transmission. The average distance between contiguous soft phase domains $\left(d_{\mathrm{i}}\right)$ was estimated from the angular location of the maximum intensity peak in the scattering curve, according to the Bragg's law.

Further, a scanning electron microscope (SEM; JSM 5400 of Jeol, Tokyo, Japan) was used to analyze the surface of the TPUs before and after erosion. Prior to SEM, the specimens were sputtered with a thin $\mathrm{Pt} / \mathrm{Pd}$ alloy layer in a Balzers SCD-050 (Balzers, Liechtenstein) sputtering device for $150 \mathrm{~s}$.

\subsection{Viscoelastic analysis}

Linear viscoelastic analyses were carried out using a dynamic mechanical analyser Metravib DMA + 1000 (ACOEM Group, France). The frequency dependent storage $\left(E^{\prime}\right)$ and loss $\left(E^{\prime \prime}\right)$ flexural moduli were evaluated in three-point bending mode by imposing a static stress of $10^{5} \mathrm{~N} / \mathrm{m}^{2}$ and a dynamic stress of $5 \cdot 10^{4} \mathrm{~N} / \mathrm{m}^{2}$. For each sample the tests were performed in a frequency range $\omega$ between 1 and $50 \mathrm{~Hz}$, at temperatures from -50 to $50^{\circ} \mathrm{C}$, i.e. a temperature range within which the glass transition of the amorphous soft phase of the different TPUs took place. The time-temperature superposition principle (TTS) was then used to generate master curves of $E^{\prime}$ and $E^{\prime \prime}$ in a broad frequency range. As reference temperature, $T=25^{\circ} \mathrm{C}$ was chosen.

\subsection{Solid particle erosion tests}

The erosive wear tests were conducted within a sand-blasting type facility (ST 800, Paul Auer GmbH, Mannheim, Germany) [7]. The erodent particles were driven and accelerated by compressed air, exiting from a steel nozzle (length $66 \mathrm{~mm}$, diameter $10 \mathrm{~mm}$ ) and impacting on the sample surface. The measurements were done according to the ASTM G76-83 standard [16].

The erodent particles utilized for the tests were angular grainy grit quartz sand F36, having different shape and a wide size range $(125-355 \mu \mathrm{m})$. The average velocity of the particles, determined by using the double disc method [17] amounted to $\sim 160 \mathrm{~m} / \mathrm{s}$. All the specimen were impacted in the erosive wear chamber at room temperature. A fixed area of $20 \mathrm{~mm}$ in diameter was exposed to a sand flow rate of $6.45 \mathrm{~g} / \mathrm{min}$ at different impact angles in a range between 15 and $90^{\circ}$. The angle $0^{\circ}$ could not be reliably determined, so that it was not further tested. The mass loss of the samples after erosion $(\Delta m)$ was measured through a precision balance (AT261 Mettler Toledo, United States), and then related to the mass of erodent $\left(m_{\mathrm{E}}\right)$, leading to the erosion rate $\Delta m / m_{\mathrm{E}}$.

\subsection{Abrasion tests}

For comparison purposes, the low velocity abrasion behaviour of the samples was also investigated by means of a custom-built scratch machine (Surface Machine Systems, LLC, Texas, USA). A square sample $\left(5 \times 5 \mathrm{~mm}^{2}\right)$ was scratched in the $y$-direction against an abrasive $\mathrm{SiC}$ - paper P180 (average particle diameter $82 \mu \mathrm{m}$ ). The normal load was $12.5 \mathrm{~N}$ (equivalent to a nominal pressure of $0.5 \mathrm{MPa}$ ), and 
the velocity amounted to $1 \mathrm{~mm} / \mathrm{s}$. The sample changes its $x$-position after each cycle to always meet a fresh portion of abrasive paper.

\section{Results}

\subsection{Microstructural analyses}

TEM analyses were carried out with the aim to identify the space arrangement of the soft and hard phases in the selected TPUs. Some representative micrographs are reported in Figure 1.

The bright and dark regions represent the hard and soft domains, respectively. The samples differ in terms of relative amounts and space arrangement of the phases. Both drop-matrix (Figure 1a and 1d) and co-continuous (Figure $1 \mathrm{~b}$ and $1 \mathrm{c}$ ) morphologies can be recognized: in the former, isolated domains (dark) of the soft phase are suspended in the hard matrix (bright); in the latter, the phases are both continuous and appear interpenetrated. Further quantitative information can be collected through SAXS analy-

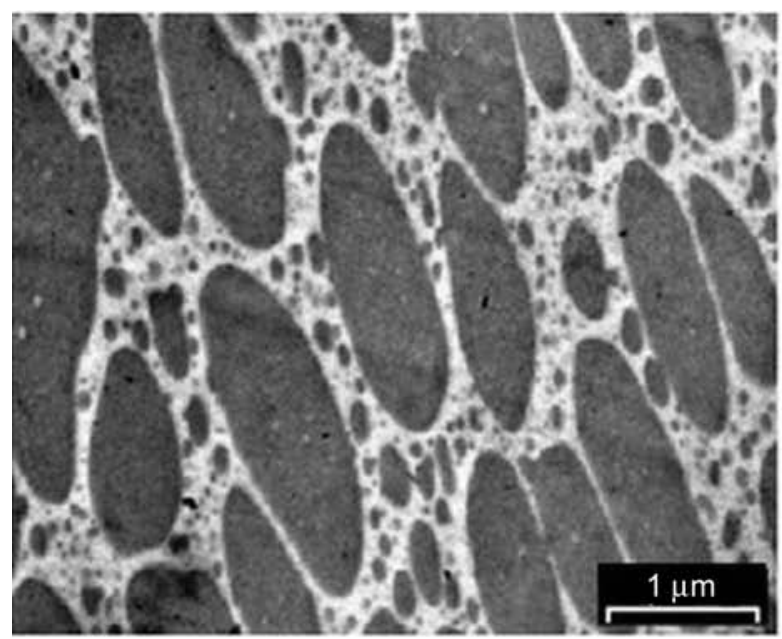

a)

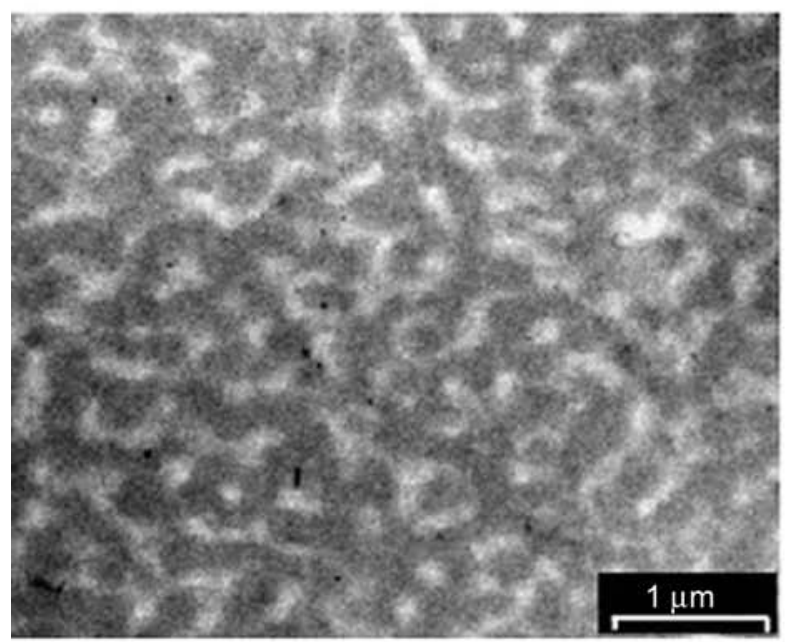

c) sis, which is often employed when dealing with polyurethane systems $[8,18]$. The one-dimensional SAXS patterns of intensity $I(q)$ vs. $q$ of the various TPUs are shown in Figure 2.

An intensity maximum in the scattering curve indicates a phase separated morphology. The peak intensity is particularly high for the samples TPU 1 and TPU 7, which clearly exhibit a drop-matrix morphology. Less intensive and broader peaks are instead

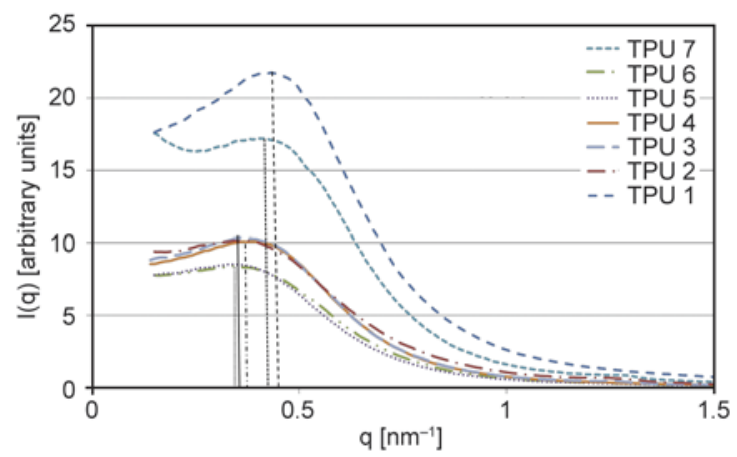

Figure 2. SAXS patterns of the TPUs

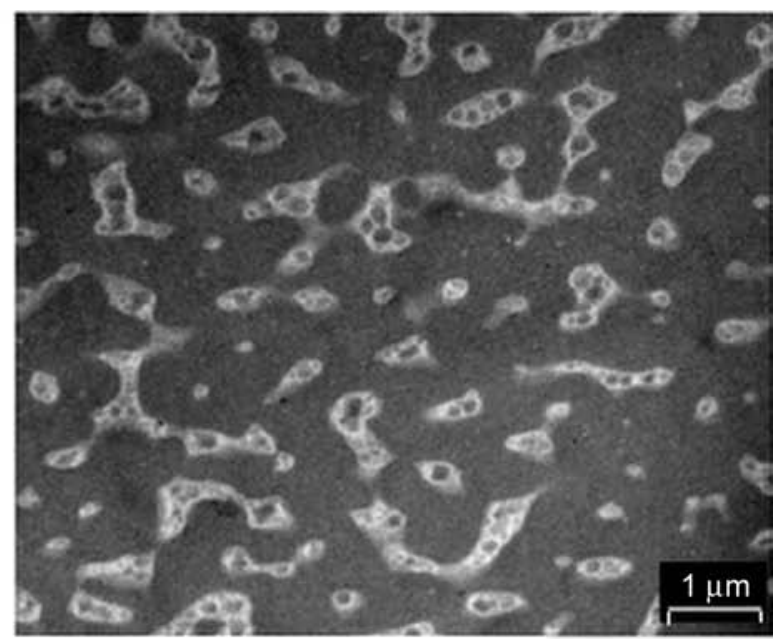

b)

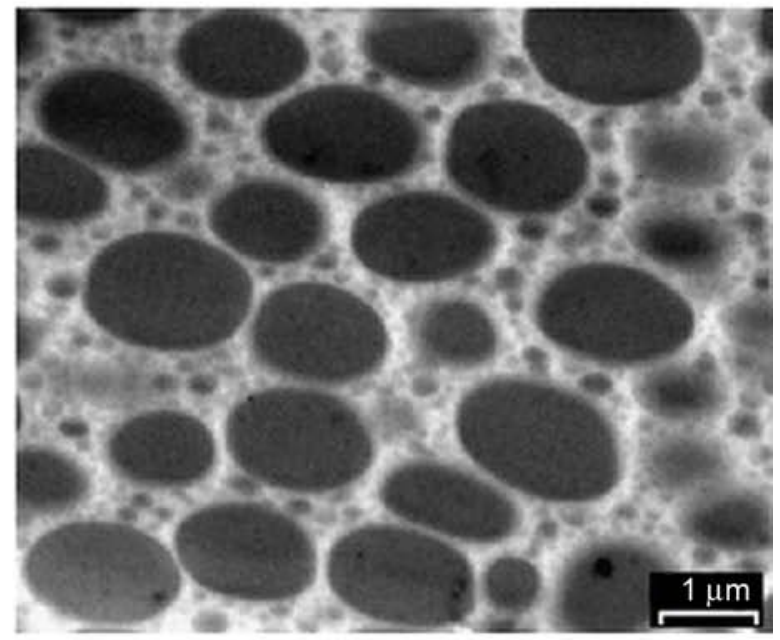

d)

Figure 1. TEM images of TPU 1 (a), TPU 3 (b), TPU 6 (c), and TPU 7 (d) 
Table 2. Average inter-domain distance computed from the SAXS spectra

\begin{tabular}{|l|c|c|c|c|c|c|c|}
\hline & TPU 1 & TPU 2 & TPU 3 & TPU 4 & TPU 5 & TPU 6 & TPU 7 \\
\hline $\begin{array}{l}q_{\max } \\
{\left[\mathrm{nm}^{-1}\right]}\end{array}$ & 0.43 & 0.37 & 0.35 & 0.39 & 0.33 & 0.33 & 0.40 \\
\hline $\begin{array}{l}d_{\mathrm{i}} \\
{[\mathrm{nm}]}\end{array}$ & 14.54 & 16.92 & 17.78 & 16.25 & 18.82 & 18.82 & 15.66 \\
\hline
\end{tabular}

noticed for the other samples, suggesting more homogeneous structures in which ordered crystalline and/or para-crystalline hard domains appear randomly dispersed in a continuous soft matrix. An approximate estimate of the average inter-domain distance can be inferred from the position of the intensity peak [18]. The data, computed by means of the Bragg's law, are listed in Table 2.

All the samples exhibit phase separation at nanoscale in addition to the superimposed morphology in larger lateral scale as depicted in the TEM-pictures, so that the $d_{\mathrm{i}}$ - data cannot be correlated directly to any features seen on the low magnification TEM pictures. The samples TPU 1 and TPU 7, i.e. those with a drop-matrix morphology, possess slightly smaller inter-domain spacing.

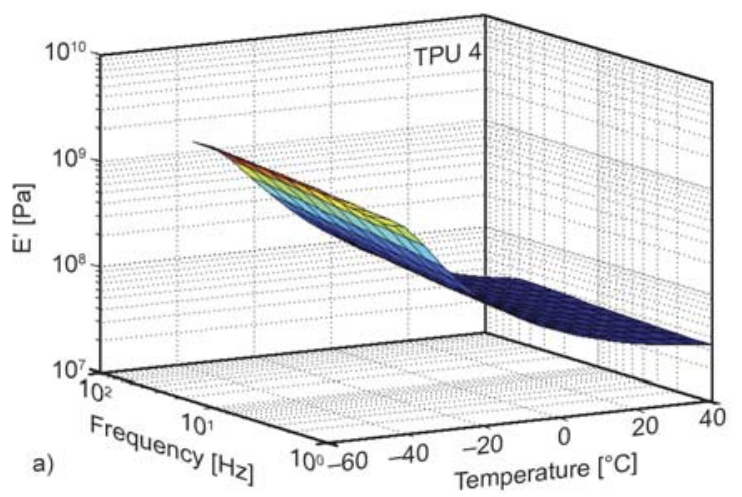

In general, the TEM and SAXS results reveal significant microstructural differences among the commercial TPU samples investigated, which are also reflected in a different macroscopic response of the materials, as shown in Table 1.

\subsection{Viscoelastic behavior}

Viscoelastic analysis is a powerful tool to collect mechanical information in a wide range of timescale or, alternatively, over different length scales. The time-temperature equivalence was exploited to enlarge the experimental time window. An example of the output of a series of viscoelastic tests is shown in Figure 3, where $E^{\prime}$ and the loss factor $\tan \delta$ of the sample TPU 4 are shown as a function of frequency and temperature.

Invoking the time-temperature superposition principle, the frequency dependence of the viscoelastic moduli was estimated in a wide range of frequency. In particular, the very short timescale involved in the erosion phenomenon produced by high momentum particles suggested to focus on the high-frequency viscoelastic behaviour, which was probed

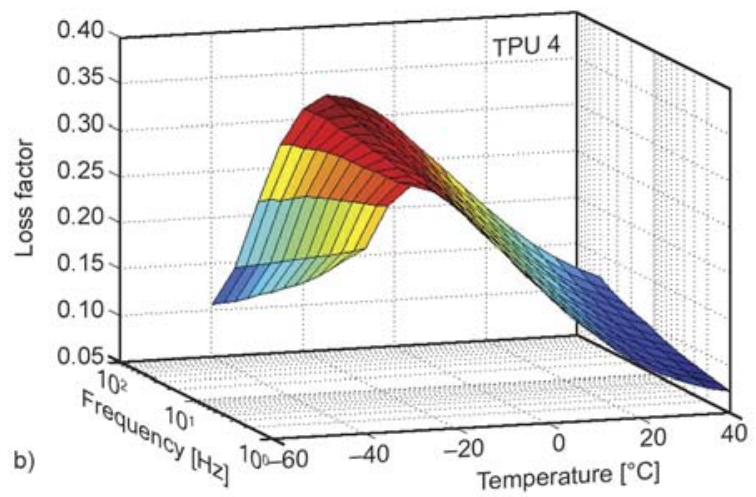

Figure 3. $E^{\prime}(\mathrm{a})$ and $\tan \delta(\mathrm{b})$ as function of temperature and frequency for the sample TPU 4
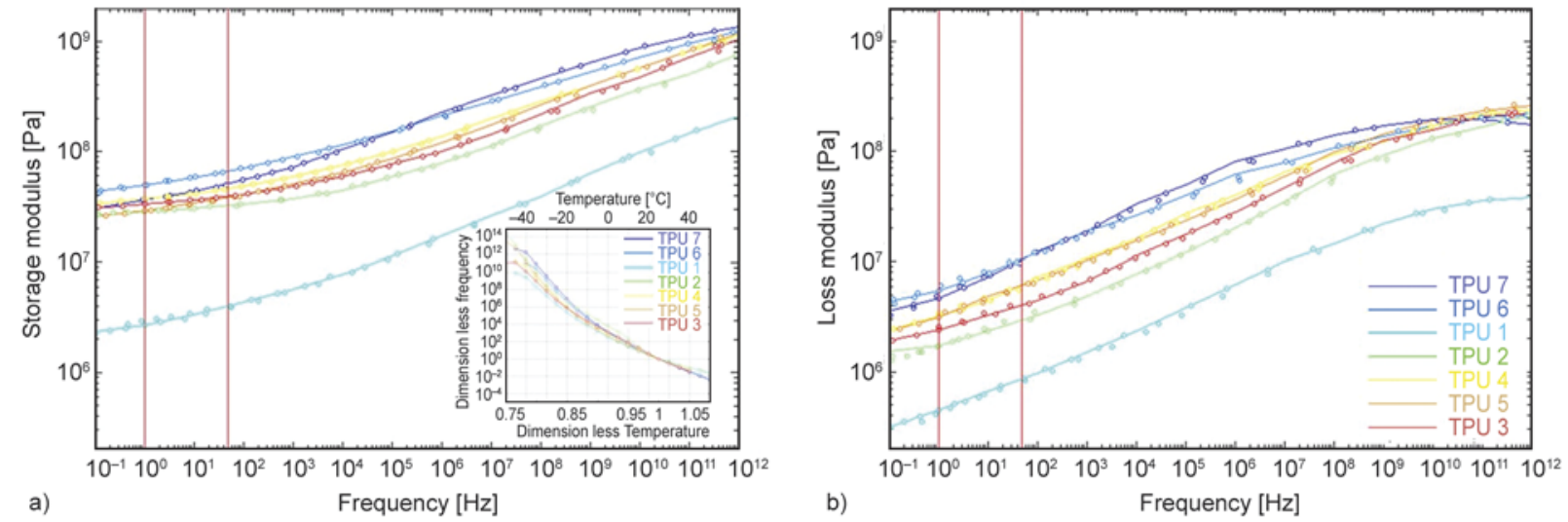

Figure 4. Master curves of $E^{\prime}$ (a) and for $E^{\prime \prime}$ (b) for the various TPUs. The reference curves at $T_{\text {ref }}=25^{\circ} \mathrm{C}$ are highlighted. The $T$-dependence of the shift factors a $T$ are shown in the inset. 
by performing low-temperature tests. The master curves of $E^{\prime}$ and $E^{\prime \prime}$ are shown in Figure 4 for the various TPUs. The reference temperature was $T_{\text {ref }}=$ $25^{\circ} \mathrm{C}$, that is the temperature at which erosion and abrasion tests were performed.

Although the curves cross each other in several points, the materials essentially share the same overall behaviour, whereby both moduli generally increase with frequency, denoting a typical viscoelastic behaviour. More precisely, the samples exhibit a predominant elastic feature, $E^{\prime}$ being much higher than $E^{\prime \prime}$ in the whole range of frequencies investigated. However, only the polycarbonate-based sample TPU 7 starts losing its viscous feature at $\sim 10^{10} \mathrm{~Hz}$, where $E^{\prime \prime}$ exhibits a maximum. Moreover, it is interesting to notice that the polyether-based sample TPU 1 differs from the others because of its relatively low moduli, which is probably due to a higher flexibility of the ether bonds in comparison with the ester and carbonate bonds of the other samples.

\subsection{Solid particle erosion}

Solid particle erosion tests have been carried out for about 30 minutes at a value of particle impact velocity of $160 \mathrm{~m} / \mathrm{s}$. Previous studies [7, 19] have shown that the wear rate does not change appreciably above values of the impingement angle $\alpha>45^{\circ}$. This can be explained by the partial embedding of the eroding silica particles into the sample, which is mostly pronounced at normal angles of impact [7]. As a consequence, the erosion tests were performed at values of $\alpha$ ranging from 15 to $45^{\circ}$. Corresponding results are shown in Figure 5.

The maximum erosion rate was found at $\alpha=15^{\circ}$, and it is assumed that it will still slightly increase with angles lower than $15^{\circ}$. This suggests that the



Figure 5. Erosive wear rate of TPUs as function of impingement angle. The points are average values of three independent tests. thermoplastic elastomers possess the lowest erosion resistance when the impingement conditions are similar to that of surface abrasion. Among the different TPUs, the polyether-based TPU 1 showed the lowest erosion rate, whereas the polycarbonate system TPU 7 exhibited the poorest erosion behaviour. The erosion rate of the various polyester-based TPUs ranged in between these two extremes.

When considering the appearance of the surfaces at the end of the tests, in the initial stage of the erosion process some particles were embedded. Once a steady state condition was reached, small cracks and a high degree of plastic deformation occurred. During the initial stage, also ridges were formed, and in the successive steps the particles impacting the surface deformed these ridges and caused some cracks normal to the erosion direction. The latter started to grow at the ridge bases. In this way, the cyclic impact caused a fatigue crack growth, with cracks intersecting to each other and causing material removal $[9,19,20]$. All these features can be found on the SEM micrographs of the worn surfaces, in this case for material TPU 4, at three different values of $\alpha$ (Figure 6). The micro-cracks and plastic deformations caused by the erosion are similar for all the impingement angles, being more intense at $\alpha=$ $15^{\circ}$. Fracture and chipping off over the surface are ascribed to the succession of impacts, which gradually increase the strain until the removal of the material.

SEM micrographs of the surfaces of the samples TPU 1 and 7 after erosion test at $\alpha=45^{\circ}$ are shown in Figure 7. Cracks, ridges and debris are visible over all the eroded surfaces. Micro-tearing and microcracks under the surface, caused by the cyclic impact of silica sand, can also be observed. The worn surface of TPU 1 mainly shows plastic deformation, with a rather limited presence of cracks and debris in comparison to TPU 7. In particular, TPU 7 shows the mostly damaged surface after erosion. This is consistent with the low erosion resistance exhibited by this sample (see Figure 5).

\subsection{Abrasion tests}

The results of the abrasion tests are reported in Figure 8 in comparison to the erosion mass loss data at $15^{\circ}$.

It is noteworthy that the TPU resistances to erosive and abrasive wear approximately follow the same trend. This confirms that, especially when the abra- 


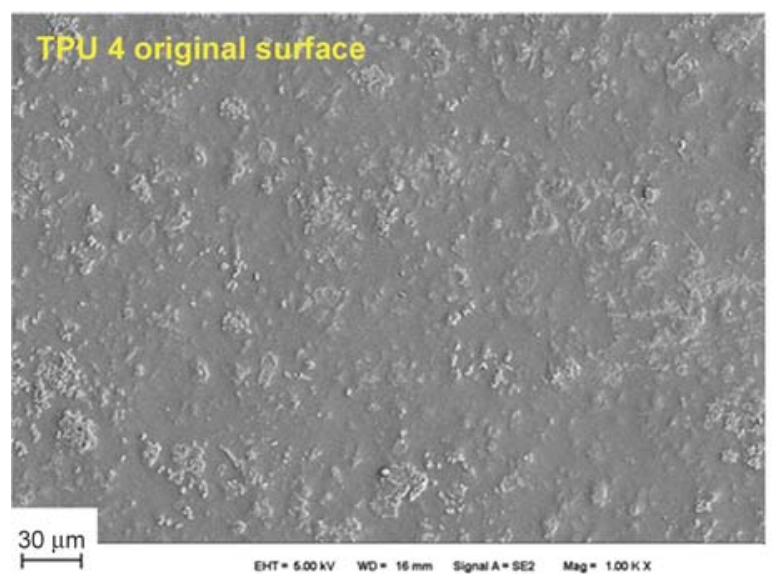

a)

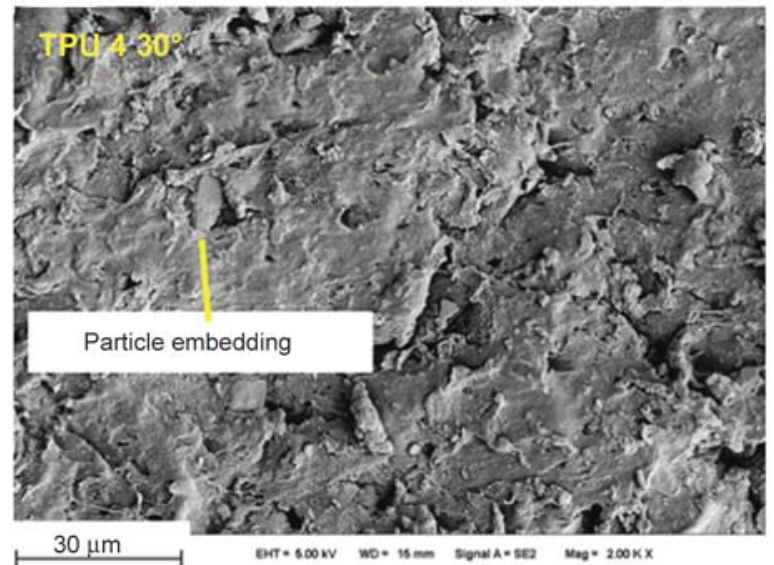

c)

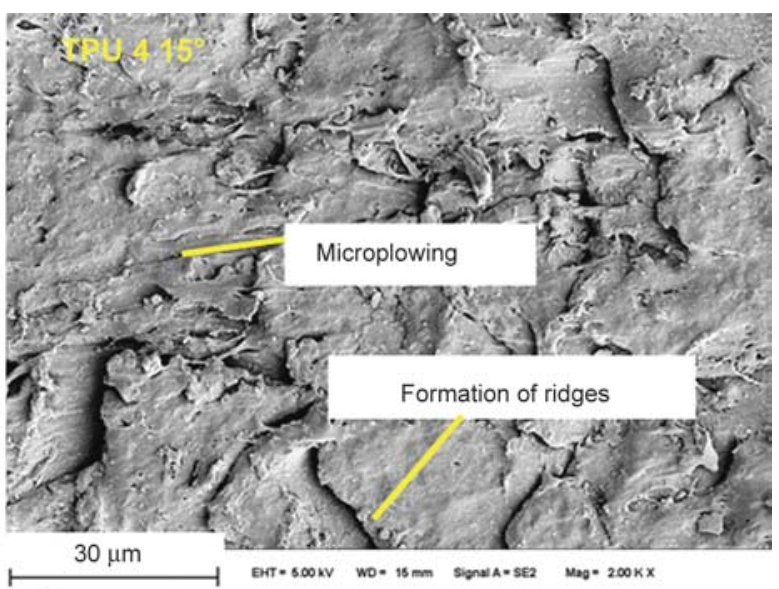

b)

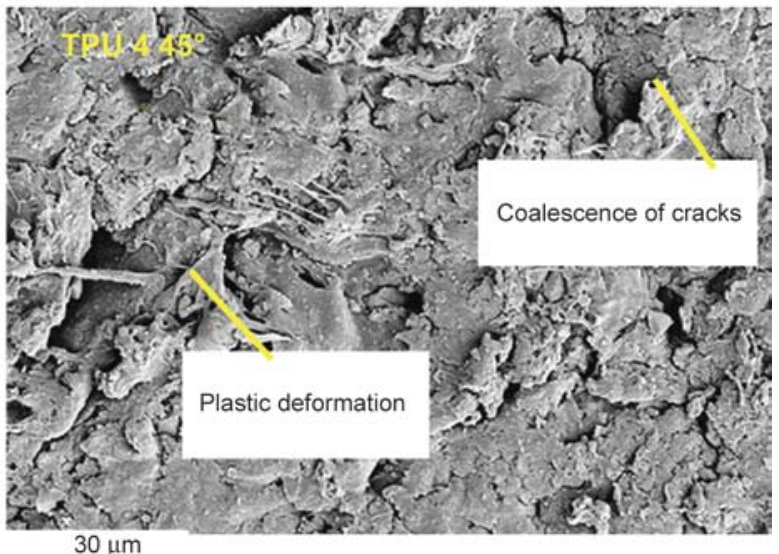

d)

Figure 6. SEM micrographs showing the surface of the sample TPU 4 before (a) and after erosion tests at $\alpha=15^{\circ}$ (b), $\alpha=$ $30^{\circ}$ (c) and $\alpha=45^{\circ}$ (d)

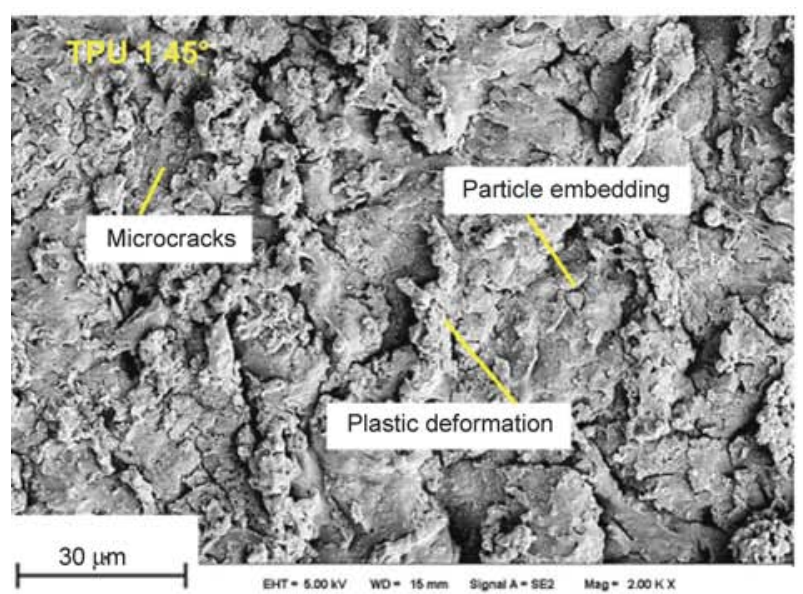

a)

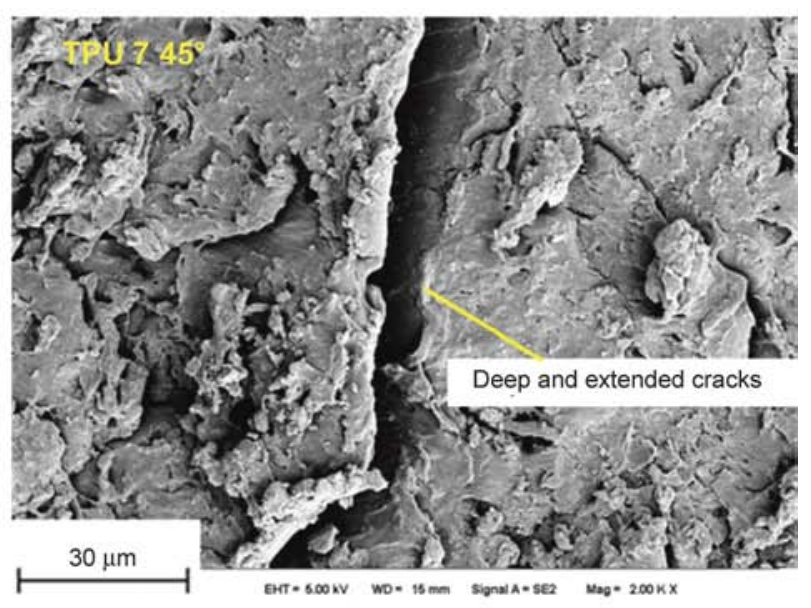

b)

Figure 7. Surfaces of the sample TPU 1 (a) and TPU 7 (b), after erosion tests at $\alpha=45^{\circ}$

sive wear is compared with the erosion at glancing impingement angles, the resistances against removal of material are quite similar.

The SEM images of TPU 2 and TPU 7 after abrasion testing are compared in Figure 9. Both samples exhibit long ploughed furrows. The lower abrasive wear resistance of sample TPU 7 is reflected in larger fragments before final removal from the specimen surface. 


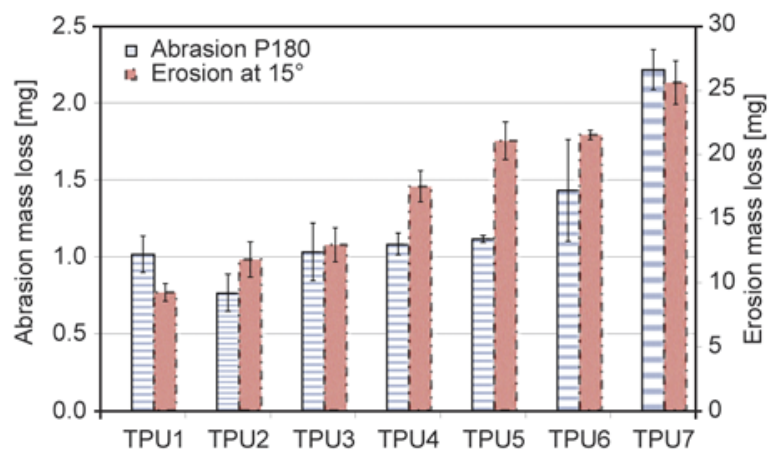

Figure 8. Comparison between the mass loss showed by the selected TPUs during erosion tests at $\alpha=15^{\circ}$ for $31 \mathrm{~min}$ (red columns) and abrasion tests on $500 \mathrm{~mm}$ of P180 abrasive paper (blue columns)

\section{Discussion}

\subsection{Comparison between mechanical properties, microstructural details and erosion rate}

When comparing the erosion rates of the TPU samples, represented by their value under $30^{\circ}$ impact angle (see Figure 5) with the mechanical properties, as listed in Table 1, no direct correlation in the trends can be found (Figure 10). This means that only a complex combination of various properties, as it has been proposed in some previous papers for a comparison of a broad variety of different polymers, e.g. [2], could help. In the present case, however, only one specific class of polymers (TPU) with slightly different chemical composition is compared, whereby all of the polymers in this class are generally very resistant against erosion. Therefore a correlation approach as mentioned above seems to be not successful at all.

Another approach to correlate the erosive wear rates with differences in the microstructural details

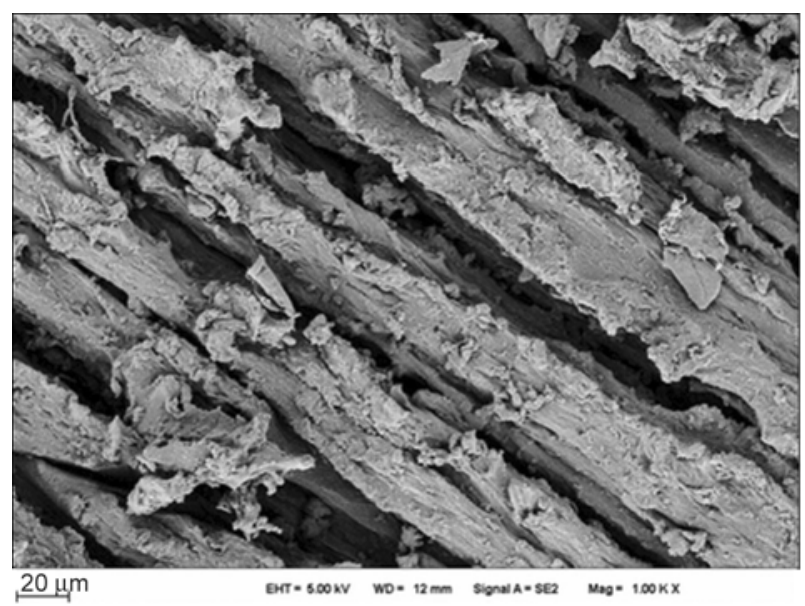

a)



Figure 10. Comparison between erosion rate $(E r)$ at $30^{\circ}$, and mechanical properties such deformation at break $\left(\varepsilon_{\mathrm{b}}\right)$, elastic modulus $(E)$, tensile strength $\left(\sigma_{\mathrm{y}}\right)$ and hardness $(H)$

(as found by TEM or SAXS) is also misleading. E.g. when comparing the TEM images of TPU 1 and TPU 7 with their erosion rates, their morphologies look very similar, but their erosion rates are totally opposite. The same is true for TPU 3 and TPU 6. And also a comparison between the erosion rates and the inter-domain spacings does not lead to any success.

In the following, it was therefore tested if the viscoelastic data, which also showed clear differences between the different TPUs allow a meaningful correlation.

\subsection{Correlation between erosion rate and viscoelastic properties}

In order to rank the samples on the basis of their viscoelastic behaviour shown in Figure 4, first of all the identification of the correct timescale relevant to the erosion testing conditions is required. The characteristic duration $\tau$ of each impact of an eroding particle on the surface of the sample can be roughly

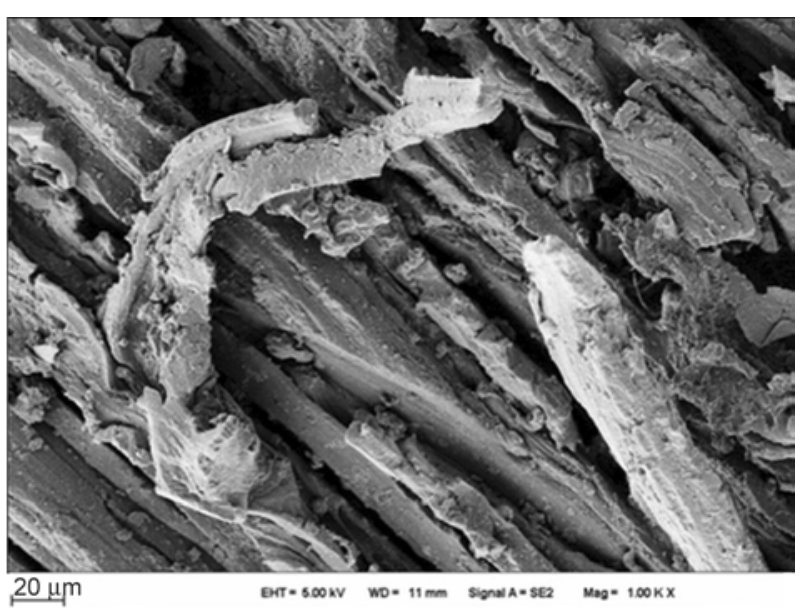

b)

Figure 9. SEM images of TPU 2 (a) and TPU 7 (b) after abrasion test on abrasive paper P180 
estimated as the ratio between the impact depth $h_{\mathrm{i}}$ and the impact velocity $v_{\mathrm{i}}$. Looking at the roughness profile of the samples at the end of the erosion test, i.e. after continued impacts have hit the surface, one can reasonably assume that $h_{\mathrm{i}} \sim 10 \mu \mathrm{m}$. We recognise that inferring $h_{\mathrm{i}}$ from head-on SEM pictures is difficult. Actually profilometry or AFM analysis would be much more appropriate. However, it can be observed that the correlation shown in Figures 11 and 12 is quite strong, i.e. it keeps holding true even if the order of magnitude of the $h_{\mathrm{i}}$ is wrong. For example, if $h_{\mathrm{i}}$ (that we inferred to be $\sim 10 \mu \mathrm{m}$ from SEM visual inspection) would be either 1 or $100 \mu \mathrm{m}$, then $\tau=h_{\mathrm{i}} / v_{\mathrm{i}}$ would be $10^{-6}$ or $10^{-8} \mathrm{~s}$, or alternatively the relevant frequency would be $10^{6}$ or $10^{8} \mathrm{~Hz}$. Looking at Figure 4, it can be concluded that this would not affect our conclusions in terms of ranking of various TPUs. Being $v_{\mathrm{i}} \sim 160 \mathrm{~m} / \mathrm{s}$, one gets a value of $\tau \sim 10^{-7} \mathrm{~s}$. This means that a meaningful comparison among the various TPU samples must be done at a frequency of $10^{7} \mathrm{~Hz}$. Therefore the viscoelastic moduli at $\omega=10^{7} \mathrm{~Hz}$ were plotted in Figure 11 as a function of the mass loss (after $30 \mathrm{~min}$ of erosion testing).

In fact, a linear correlation is noticed between the mass loss and the viscoelastic moduli at the frequency of interest, irrespective of the impingement angle. In particular, the higher the viscoelastic moduli, the higher the erosion rate. It is important to observe that such a direct correlation is quite robust, persisting in a pretty wide range of frequencies around $\omega=10^{7} \mathrm{~Hz}$. Consequently, even non-negligible uncertainty on $h_{\mathrm{i}}$ or $v_{\mathrm{i}}$ does not invalidate our main conclusions. The strict relationship becomes even more evident by considering the viscoelastic moduli divided by $\Delta m$ (Figure 12). More specifi-

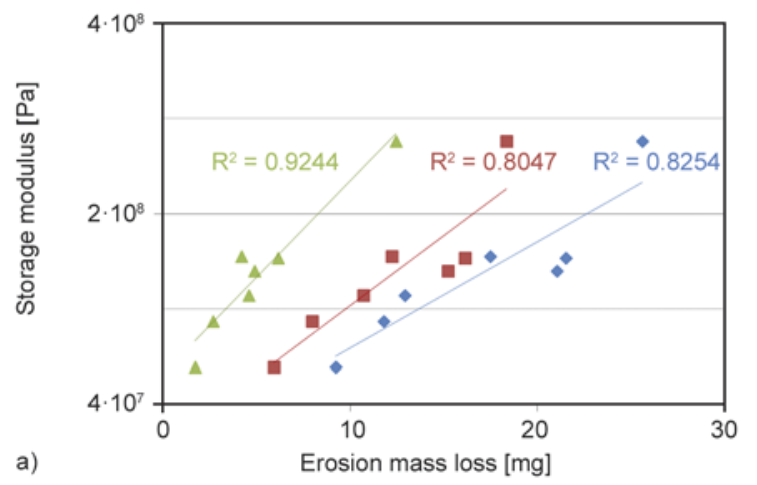

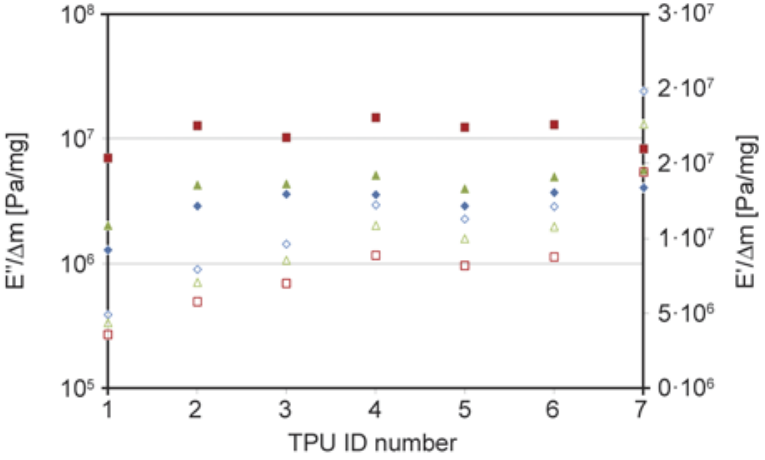

Figure 12. Storage (empty symbols) and loss (full symbols) modulus at $\omega=10^{7} \mathrm{~Hz}$ divided by the mass loss for all the TPUs tested at the various angles of impact: $15^{\circ}$ (diamonds), $30^{\circ}$ (squares) and $45^{\circ}$ (triangles)

cally, an essential independence on the type of TPU and impingement angle can be noticed for the parameter $E^{\prime \prime} / \Delta m$. In other words, all the TPUs share the same erosion resistance if the comparison is done in terms of their loss modulus.

Provided to be estimated at the proper frequency, the loss modulus seems to be the critical property for the erosion resistance of the studied TPUs. The relevance of $E^{\prime \prime}$ could reflect the noticeable propensity to plasticization exhibited by polymeric materials even in case of impulsive loads [21]. It is worth noting that the importance of energy dissipation was also highlighted by Karger-Kocsis and Kuleznev [22], who noticed a good correlation between impact strength and $\tan \delta$ in impact modified polypropylene.

\section{Conclusions}

Various commercial TPUs were studied in terms of morphological and tribological features and linear viscoelastic behavior. TEM and SAXS analyses

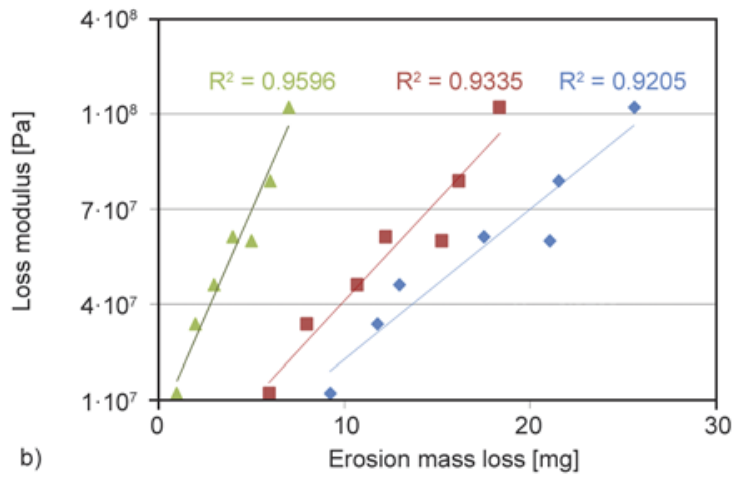

Figure 11. Storage (a) and loss (b) modulus at $\omega=10^{7} \mathrm{~Hz}$ as a function of the mass loss at various impingement angles: $15^{\circ}$ (blue diamonds), $30^{\circ}$ (red squares) and $45^{\circ}$ (green triangles). Lines are linear fittings to the experimental data. The coefficient of determination $R^{2}$ is reported for each dataset. 
reveled that the samples exhibit different morphologies. In particular, the soft phase can be in the form of either isolated drops or continuous domains interpenetrated with the hard phase. Abrasion tests showed a good correlation with erosion measurements carried out at impingement angle below about $15^{\circ}$. This means that abrasion tests can be used for a first screening of ductile polymeric materials, which are supposed to have their erosion maximum close to an angle of 0 to $15^{\circ}$. The analysis of the viscoelastic behavior revealed a good relationship between the erosion mass loss and the loss modulus, provided the latter is estimated in the proper timescale, i.e. the one of the impacts of the erodent particles. Accordingly, we focused on the viscoelastic properties at about $10^{7} \mathrm{~Hz}$. Good linear correlation was found between $E^{\prime \prime}$ and the mass loss in the course of the erosion tests irrespective of the impingement angle. The ability to rationalize erosion data of many different TPUs suggests that the viscous modulus is the key parameter in the erosion resistance of the studied materials. This has been explained by invoking the inherent propensity to plasticization of the elastomers.

\section{Acknowledgements}

This work was partially supported by the Italian Ministry of University (MIUR) through the project PON01_00519 SCILLA_M. Authors are grateful to Dr. Luigi Sanguigno for his precious support in the DMA analyses and the precious discussions about the TTS principle. One of us, G. Arena, is especially grateful to the ERASMUS Program, allowing him the nine months research stay at the Institute for Composite Materials (IVW GmbH), Kaiserslautern, Germany, where many of the experiments were carried out.

\section{References}

[1] Barkoula N-M., Karger-Kocsis J.: Review processes and influencing parameters of the solid particle erosion of polymers and their composites. Journal of Materials Science, 37, 3807-3820 (2002).

DOI: $10.1023 / \mathrm{A}: 1019633515481$

[2] Friedrich K.: Erosive wear of polymer surfaces by steel ball blasting. Journal of Materials Science, 21, 3317-3332 (1986).

DOI: $10.1007 / \mathrm{BF} 00553375$

[3] Barkoula N-M., Karger-Kocsis J.: Solid particle erosion of unidirectional GF reinforced EP composites with different fiber/matrix adhesion. Journal of Reinforced Plastics and Composites, 21, 1377-1388 (2002). DOI: $10.1177 / 0731684402021015779$
[4] Pei X-Q., Friedrich K.: Erosive wear properties of unidirectional carbon fiber reinforced PEEK composites. Tribology International, 55, 135-140 (2012). DOI: $10.1016 /$ j.triboint 2012.05 .020

[5] Stachowiak G. W., Batchelor A. W.: Engineering tribology. Butterworth-Heinemann, Dordrecht (2005).

[6] Slikkerveer P. J., van Dongen M. H. A., Touwslager F. J.: Erosion of elastomeric protective coatings. Wear, 236, 189-198 (1999). DOI: $10.1016 / \mathrm{S} 0043-1648(99) 00268-9$

[7] Friedrich K., Pei X-Q., Almajid A. A.: Specific erosive wear rate of neat polymer films and various polymer composites. Journal of Reinforced Plastics and Composites, 32, 631-643 (2013).

DOI: $10.1177 / 0731684413478478$

[8] Prisacariu C.: Polyurethane elastomers. From morphology to mechanical aspects. Springer, Wien (2011). DOI: $10.1007 / 978-3-7091-0514-6$

[9] Sigamani N. S.: Characterization of polyurethane at multiple scales for erosion mechanisms under sand particle impact. Master's thesis, Texas A\&M University, USA (2010).

DOI: http://hdl.handle.net/1969.1/ETD-TAMU-201005-8008

[10] Kontou E., Spathis G., Niaounakis M., Kefalas V.: Physical and chemical cross-linking effects in polyurethane elastomers. Colloid and Polymer Science, 298, 636-644 (1990). DOI: $10.1007 / \mathrm{BF} 01410405$

[11] Hutchings I. M., Deuchards W. T., Muhr A. H.: Erosion of unfilled elastomers by solid particle impact. Journal of Materials Science, 22, 4071-4076 (1987). DOI: 10.1007/BF01133360

[12] Karger-Kocsis J.: Dry friction and sliding behavior of organoclay reinforced thermoplastic polyurethane rubbers. Kautschuk, Gummi, Kunstoffe, 59, 537-543 (2006).

[13] Cizmas P. G., Slattery J. C.: Dimensionless correlation for sand erosion of families of polymers. Wear, 262, 316-319 (2007).

DOI: $10.1016 /$ j.wear.2006.05.008

[14] Li J., Hutchings I. M.: Resistance of cast polyurethane elastomers to solid particle erosion. Wear, 135, 293303 (1990). DOI: 10.1016/0043-1648(90)90032-6

[15] Li C., Goodman S. L., Albrecht R. M., Cooper S. L.: Morphology of segmented polybutadiene-polyurethane elastomers. Macromolecules, 21, 2367-2375 (1988). DOI: $10.1021 / \mathrm{ma} 00186 \mathrm{a} 012$

[16] ASTM-G76-83: Standard practice for conducting erosion tests by solid particle impingement using gas jets (1989).

[17] Ruff A. W., Ives L. K.: Measurement of solid particle velocity in erosive wear. Wear, 35, 195-199 (1975). DOI: 10.1016/0043-1648(75)90154-4 
[18] Saiani A., Rochas C., Eeckhaut G., Daunch W. A., Leenslag J-W., Higgins J. S.: Origin of multiple melting endotherms in a high hard block content polyurethane. 2. Structural investigation. Macromolecules, 37, 1411-1421 (2004).

DOI: $10.1021 / \mathrm{ma} 034604+$

[19] Acierno D., Sanguigno L., Arena G., Friedrich K., Padenko E., Russo P.: Erosion behavior and mechanical properties of thermoplastic polyurethanes. In 'Proceedings of the $7^{\text {th }}$ International Conference on Times of Polymers (TOP) and Composites, Ischia, Italy'. AIP Publishing Vol. 1599, 110-113 (2014).

DOI: $10.1063 / 1.4876790$
[20] Arnoldt J. C., Hutchings I. M.: A model for the erosive wear of rubber at oblique impact angles. Journal of Physics D: Applied Physics, 25, A222-A229 (1992).

DOI: $10.1088 / 0022-3727 / 25 / 1 \mathrm{~A} / 034$

[21] Grellmann W., Seidler S.: Deformation and fracture behaviour of polymers. Springer, Berlin (2001).

DOI: $10.1007 / 978-3-662-04556-5$

[22] Karger-Kocsis J., Kuleznev V. N.: Dynamic mechanical and impact properties of polypropylene/EPDM blends. Polymer, 23, 699-705 (1982). DOI: 10.1016/0032-3861(82)90054-4 